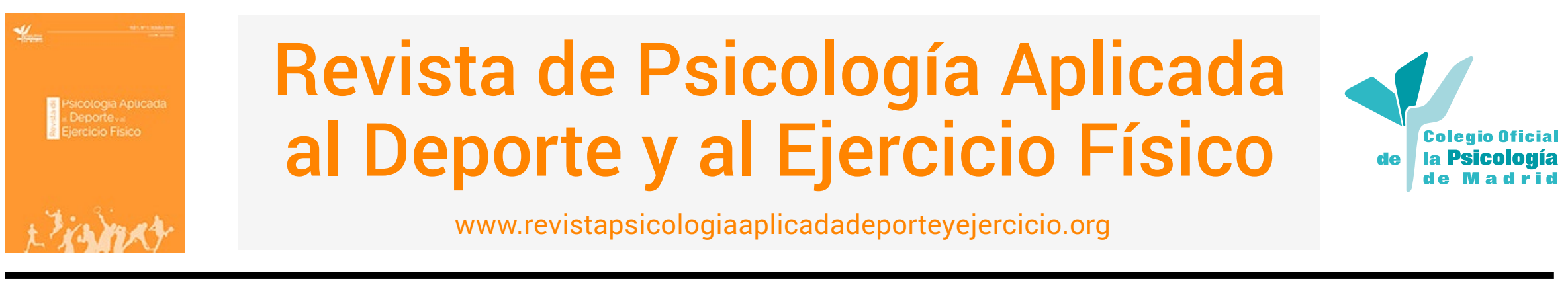

\title{
Entrevista a Vicente Martínez Orga
}

\section{Por Alejo García-Naveira}

"Una persona con un perfecto conocimiento de las federaciones deportivas, que vive por y para ellas"

Vicente es presidente de la Unión de Federaciones Deportivas Madrileñas (UFEDEMA) desde el año 2016. Antes fue presidente de la Federación Madrileña de Tiro con Arco (2000-2015), y en la actualidad, además, es presidente de la Federación Española de Tiro con Arco. También ha sido miembro de la Junta Directiva de la Federación Española de Balonmano durante 4 años y Presidente de su Junta Electoral durante 8 años, así como tesorero de la Federación Española de Rugby durante 11 años. Además, estuvo muy vinculado al deporte universitario de Madrid como secretario técnico, director técnico, vicepresidente y presidente en funciones de la Federación de Deporte Universitario de Madrid.

Por último, señalar que Vicente es ingeniero informático por la Universidad Politécnica de Madrid y profesor titular del Departamento de Inteligencia Artificial de dicha universidad, además de deportista y árbitro de tiro con arco.

Desde la Revista de Psicología Aplicada al Deporte y al Ejercicio Físico (RPADEF), estamos agradecidos por su disponibilidad para realizar esta entrevista y acercar la Psicología del Deporte a las federaciones deportivas madrileñas.

\section{Breve reseña de UFEDEMA}

La Unión de Federaciones Deportivas Madrileñas (UFEDEMA) nace en el año 1989 con el objetivo de aunar a las federaciones madrileñas en un órgano que pudiera defender sus derechos y reivindicaciones con una voz única, el problema existente en aquellos momentos donde la comunicación entre (las que entonces existían) nuestras federaciones no eran ni fácil ni sencillo. Por ello la labor que ha desarrollado y, sigue desarrollando, UFEDEMA es de vital importancia en el desarrollo del deporte madrileño, siempre hemos sido atendidos por nuestra Comunidad en muchas de nuestras demandas, pero indudablemente la sensibilidad que esta mostrando el equipo de deportes actual, con su Consejero y Viceconsejero a la cabeza es encomiable en momentos tan difíciles como los actuales.

El 14 de junio de 2018 tuvo lugar la firma del convenio de colaboración entre UFEDEMA y el COPM, ¿Qué representa esta alianza para UFEDEMA?
"Un convenio para el avance y desarrollo del deporte madrileño"

La firma de este convenio viene a rellenar un vacío importante en la concepción de la práctica deportiva en muchas de nuestras federaciones. Los más jóvenes requieren un crecimiento personal y deportivo a nivel psicológico, mientras que los deportistas de alto rendimiento necesitan de un entrenamiento mental para mejorar sus ejecuciones.

Bien es cierto que, el psicólogo/a no es una figura que haya existido históricamente en muchas de nuestras entidades y en sus clubes, por ello es necesario una campaña de concienciación de que no se debe ver como una figura superflua, sino que debe contemplarse como un elemento de vital importancia si queremos aumentar nuestros avances técnicos/deportivos, el grado de satisfacción en la práctica física/deportiva y el desarrollo integral de los deportistas. Por lo anterior, el convenio establecido entre las dos entidades debería servir para alcanzar las cotas más altas del deporte madrileño. 
Desde tu experiencia, ¿qué necesidades psicológicas tienen los deportistas y equipos de deporte base?

"El entrenamiento psicológico como complemento para la mejora"

Toda persona que desarrolla una actividad física precisa de ayuda, bien para mantener su motivación o bien para elevar el grado de satisfacción de esa práctica física y/o deportiva. No creo que debamos diferenciar las necesidades entre deportistas de distintos niveles. En una actividad donde las personas llevan su cuerpo más allá de su rutina ordinaria siempre es necesario estar preparado psicológicamente para ese esfuerzo. Esta preparación no siempre es posible obtenerla por uno mismo, sino que necesitamos la ayuda de profesionales que algunas veces complementen nuestra voluntad y otras, sean el carburante necesario para seguir adelante.

\section{¿Y los deportistas y equipos de alto rendimiento?}

"La preparación psicológica para afrontar la máxima exigencia"

Me remito a la pregunta anterior, TODOS los deportistas necesitan de la ayuda de un psicólogo/a, independientemente de su grado de rendimiento, indudablemente un deportista de alto rendimiento tiene unas exigencias superiores en cuanto a los logros y objetivos (asociado habitualmente a más recursos), y por tanto, necesita más ayuda, pero no creamos que todos estamos exentos de la necesidad de ayuda de un profesional de la Psicología si queremos desarrollar mucho mejor nuestra actividad deportiva.

¿Qué destacarías como necesidad psicológica en los deportistas de tiro con arco para mejorar su rendimiento?

"La autorregulación emocional y la concentración como base de la precisión deportiva"

Cualquier deporte en el que la concentración y la precisión sea un elemento imprescindible, requiere de una ayuda en los procesos cognitivos que el deportista tiene que afrontar para alcanzar las metas que desea. Sería indistinto el tipo de modalidad deportiva (i.e. esgrima, judo, tiro con arco). Si bien los deportes individuales, donde no puedes compartir la responsabilidad de las decisiones con otros compañeros, en principio serían más exigentes que los deportes colectivos, todos los deportes precisan de ayuda en mayor o menor grado para alcanzar una adecuada preparación psicológica. Difícilmente se entendería una exigencia de unas metas sin la ayuda de los profesionales necesarios. Pensamos que precisamos de refuerzos, pero muchas veces no somos capaces de ver el salto cualitativo que un psicólogo/a puede producir en el desarrollo de nuestra actividad físico-deportiva.

\section{¿Cuál sería el perfil ideal del entrenador en deporte base?}

\section{"Se requieren entrenadores-educadores"}

Lo que podemos entender por deporte base precisa de personas con niveles aceptables de conocimientos del deporte que se trate y sobre todo precisa de una gran disciplina formadora. Es una etapa de gran importancia, algunos no llegarán a ser deportistas de élite, pero mantendrán a lo largo del tiempo grandes valores que adquirieron a través de la práctica deportiva y que de otra forma quizás no hubieran podido adquirir.

\section{¿Y cuál sería el perfil en alto rendimiento?}

\section{"Liderar tanto lo deportivo como lo personal del deportista"}

En esta fase de un deportista, su entrenador debe transmitirle la ilusión por el trabajo duro, el esfuerzo infinito por alcanzar los objetivos, el no dejar que el desánimo haga mella en el deportista cuando piensa que no puede, que no llega, que no consigue. Para toto ello resulta esencial la presencia de un/a profesional de la psicología. Llega un momento que un deportista de alto nivel precisa más de un amigo y compañero que de un entrenador, alguien que le conozca perfectamente y sabe sus necesidades de todo tipo; físicas y mentales. Los deportistas de alto nivel, muchísimas veces, están entrenados por personas que nunca alcanzaron los resultados deportivos de sus pupilos. Ello demuestra que, si bien su rol es muy necesario, en algunos casos los aspectos emocionales priman sobre la parte técnica.

Principalmente, en que puede aportar un psicólogo/a del deporte a los deportistas, entrenadores y familiares de las diferentes federaciones y clubes deportivos de la Comunidad de Madrid.

"El psicólogo/a contribuye al crecimiento personal y desarroIlo deportivo"

Un psicólogo/a siempre aporta valores importantes a las personas y, especialmente a los deportistas, personalmente pienso que su ayuda y colaboración es imprescindible para tener un correcto desarrollo de nuestras actividades. En primer lugar, ayudaría a los deportistas y en segundo lugar a las familias. A veces los padres desconocen cómo pueden ayudar a sus hijos/as en esa lucha de querer y no poder. Un/a profesional de la psicología es necesario en la orientación de los progenitores en los momentos de desánimo y de abandono de nuestros hijos. Nadie mejor que los profesionales de 
los procesos cognitivos y emocionales para ayudarnos a la hora de afrontar la educación deportiva de nuestros hijos/as.

Para terminar, nos gustaría que pudieras compartir un mensaje para la población deportiva y psicólogos/as de la Comunidad de Madrid.

"Creced como personas y deportistas... y aspirad a lo máximo"

Tenemos la suerte de vivir en una gran Comunidad a todos los niveles, pero especialmente en el deportivo. Los logros de nuestros deportistas no son comparables ni a las ayudas que tienen, ni a los medios de los que disponen para desarrollar su actividad. Cuando veo los resultados deportivos que cosechamos pienso en lo grandes que somos. Nuestra Comunidad, por las razones que sea, dispone de un tejido deportivo increíble, el esfuerzo económico que las familias realizan para que sus miembros puedan realizar una actividad físico-deportiva es encomiable. Si vemos las aportaciones públicas de otros países (e incluso de otras comunidades de nuestro país) no se puede entender cómo los madrileños y madrileñas pueden estar en niveles competitivos tan altos. Por eso, les digo que si hemos llegado a estos niveles de excelencia no abandonemos ahora. Vamos a seguir apostando por crecer como deportistas y personas y que nuestras selecciones sean temidas en cualquier lugar donde tengamos que confrontarnos. 